\title{
La gramática escolar española entre dos siglos (1780-1813) : la sintaxis
}

María José García Folgado

\section{(2) OpenEdition}

Edición electrónica

URL: https://journals.openedition.org/dhfles/2306

DOI: 10.4000/dhfles.2306

ISSN: 2221-4038

Editor

Société Internationale pour l'Histoire du Français Langue Étrangère ou Seconde

Edición impresa

Fecha de publicación: 1 diciembre 2002

Paginación: 126-144

ISSN: 0992-7654

\section{Referencia electrónica}

María José García Folgado, « La gramática escolar española entre dos siglos (1780-1813) : la

sintaxis ", Documents pour l'histoire du français langue étrangère ou seconde [En ligne], 29 | 2002, mis en ligne le 01 janvier 2013, consulté le 27 mai 2021. URL : http://journals.openedition.org/dhfles/2306 ;

DOI : https://doi.org/10.4000/dhfles.2306

Este documento fue generado automáticamente el 27 mayo 2021.

(C) SIHFLES 


\title{
La gramática escolar española entre dos siglos (1780-1813) : la sintaxis
}

\author{
María José García Folgado
}

\section{Introducción}

1 El periodo comprendido entre finales del siglo XVIII y principios del XIX es determinante para el desarrollo de la teoría gramatical española. Este desarrollo se produce por un aumento de las inquietudes gramaticales de nuestros teóricos, que es consecuencia directa de la aparición y evolución de la gramática de la propia lengua como disciplina escolar ${ }^{1}$.

Entre 1780 y 1813, la gramática castellana se convierte en una pieza indispensable del currículo escolar, tanto en las primeras letras como en la educación secundaria. La primera de las dos fechas corresponde a la aprobación por el gobierno de Carlos III de los Estatutos del Colegio Académico de Primeras Letras (22 de diciembre de 1780), en los que, entre otras cosas, se ordena que «en todas las escuelas del reino» se enseñe «a los niños su lengua nativa por la gramática que ha compuesto y publicado la Real Academia de la Lengua; previniendo que a ninguno se admita a estudiar latinidad sin que conste antes estar bien instruido en la gramática española $»^{2}$. La segunda fecha corresponde a la realización del proyecto de reforma general de la enseñanza de $1813^{3}$, que supone el triunfo definitivo del castellano en el ámbito educativo (Aguilar Piñal 1988: 76); este triunfo viene dado por la aceptación oficial del castellano como lengua de la universidad y su imposición como materia obligatoria en la enseñanza secundaria. La incidencia de estos hechos se aprecia claramente al hacer un cómputo de las obras gramaticales para españoles que se publican desde los orígenes de la gramatización del español en 1492 con la obra nebrisense, hasta nuestro límite superior : entre 1492 y 1779 apenas se publican una decena de obras, mientras que en los escasos 33 años que cubre nuestra investigación, esa cantidad se multiplica por cuatro, como se puede apreciar en el siguiente gráfico : 


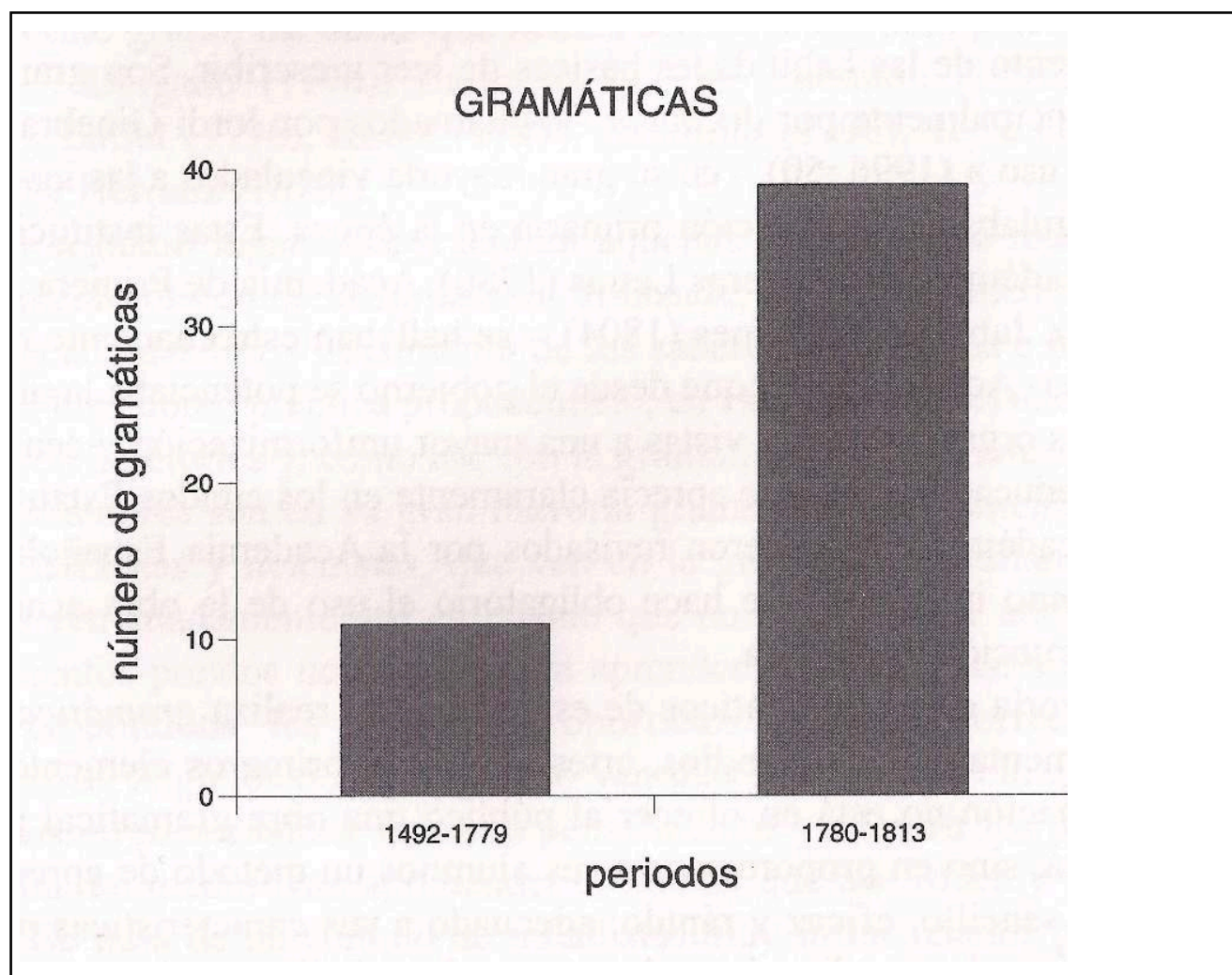

En el periodo que estudiamos, tanto en la educación primaria como en la secundaria se produce el establecimiento del castellano como disciplina escolar completa : se admite primero la práctica del castellano como lengua de trabajo en el aula y se elaboran útiles pedagógicos, gramáticas principalmente, escritos en castellano y que versan sobre el castellano. De ahí que se escriban gran cantidad de obras de calidad diversa destinadas a la enseñanza del idioma patrio, entre las que podemos establecer dos grandes grupos teniendo en cuenta el nivel de estudio para el cual la obra fue concebida :

- gramáticas para la educación primaria, orientadas al aprendizaje de la lectura y la escritura, y

- gramáticas dedicadas a la educación secundaria, bien destinadas a la formación del intelecto, a la adquisición de reglas fundadas en la razón que permitirán el acceso a otros conocimientos, bien como apoyo para el aprendizaje de otras lenguas, principalmente el latín.

Se trata, por un lado, de manuales destinados a las primeras letras, al perfeccionamiento de las habilidades básicas de leer y escribir. Son gramáticas escritas principalmente por docentes -los llamados por Jordi Ginebra "gramáticos de uso " (1996: 50)- en su gran mayoría vinculados a las instituciones que regulaban la instrucción primaria en la época. Estas instituciones -Colegio Académico de Primeras Letras (1780), Academia de Primera Educación (1791), Junta de exámenes (1804)- se hallaban estrechamente relacionadas con las Academias, ya que desde el gobierno se potenciaba la unión de sus diversos organismos con vistas a una mayor uniformización y centralización de la educación ; esto se aprecia claramente en los citados Estatutos del Colegio Académico, que fueron revisados por la Academia Española, y en los que, como indicamos, se hace obligatorio el uso de la obra académica para la instrucción lingüística. 
5 La mayoría de los gramáticos de este grupo no realiza gramáticas, sino obras rudimentarias, compendios, artes, diálogos, primeros elementos, etc. Su preocupación no está en ofrecer al público una obra gramatical propiamente dicha, sino en proporcionar a sus alumnos un método de aprendizaje gramatical sencillo, eficaz y rápido, adecuado a sus características particulares. Un ejemplo paradigmático de esto es el de Guillermo Antonio Cristóbal y Jaramillo, quien indica claramente que su tratado no está destinado a

establecer un verdadero arte completo de la lengua española, que esto ya lo ha hecho con todo primor la Real Academia de la Lengua, sino a deducir un método sobresaliente, breve y compendioso de enseñarla, estableciendo reglas fijas, verdaderas y corrientes, entresacándolas de los mejores autores, observando siempre el espíritu y precepto de dicho Real cuerpo, e inventando algunas, que el uso constante, el trastorno de los tiempos, y la comunicación continua con los extranjeros nos fuercen a seguirla y abrazarla $(1800: 13)$.

6 A pesar de esto, las variadas obras de primera educación que hemos consultado no son un mero remedo de los tratados académicos y en ellas se pueden encontrar tanto aportaciones originales, como las más diversas influencias; así, por ejemplo, en la citada obra de Jaramillo (1800) se aúna la tradición autóctona reflejada en la gramática académica de 1796 (cuarta edición) con las ideas provenientes del racionalismo inglés, a través de la traducción de las obras del escocés H. Blair (García Folgado 2002).

7 En este grupo, las obras que hemos seleccionado son, por orden cronológico : Delgado (1790), Balbuena (1791), Anónimo (1792), Jaramillo (1793), Ballot (1796), Rubel (1797), Jaramillo (1798), Torio (1798), Torio (1802) y Herranz (18156).

8 En segundo lugar, se encuentran aquellas obras que se redactan como instrumento básico en la formación avanzada, bien como medio para organizar la adquisición y tratamiento de los saberes lingüísticos e incluso científicos, bien como práctica propedéutica; en este nivel, la relación con la lógica, con la retórica y, cómo no, con la gramática latina, es intensa.

9 Los autores son en su gran mayoría gramáticos propiamente dichos, es decir, latinistas y helenistas, que ven en la gramática castellana un instrumento extremadamente útil en cuanto que no sólo permite adquirir los conocimientos previos necesarios para aprender otras lenguas, sino que también proporciona los elementos oportunos para un correcto dominio idiomático. Algunos de ellos incluso van más allá y ven en la gramática un mecanismo para analizar nuestros pensamientos y adquirir los principios de la razón, un medio para aprehender el mundo que nos rodea y poder explicarlo. Se trata de un cúmulo de tratadistas muy influenciados por las ideas del racionalismo y su aprovechamiento de la gramática general, aunque en muy pocos casos se trate propiamente de ésta.

10 A partir de esas ideas, un reducido número de autores redacta manuales destinados a escuelas técnicas o militares, en las que no se enseña latín, aunque sí lenguas modernas; así ocurre, por ejemplo, con Jovellanos, quien no es propiamente un gramático, sino un pensador que deja el plano de lo teórico para llevar a la práctica sus ideas educativas en el Instituto Asturiano de Mineralogía, donde aplica los postulados de Condillac (especialmente, del Cours d'étude pour l'instruction du Prince de Parme, 1775) expuestos en su Curso de Humanidades Castellanas (circa 1795); para Jovellanos, la gramática facilita a los alumnos la comprensión de los procesos lingüísticos, lo que conlleva que sus realizaciones lingüísticas alcancen un mayor grado de elaboración, así 
como que les resulten transparentes los mecanismos del lenguaje y la relación entre el contenido y la forma. Jovellanos entiende que el lenguaje es un producto social y como tal, un individuo socialmente apto ha de dominarlo en todas sus facetas.

11 Sin embargo, el grueso de la producción en la secundaria está representado por obras destinadas al aprendizaje de la gramática latina, la cual sigue siendo un paso necesario para el acceso a los estudios universitarios. Esto determina que, en gran medida, la dependencia teórica del modelo latino siga siendo muy acusada en los aspectos morfosintácticos. Los autores que hemos considerado en este nivel son: González Valdés (1791), Muñoz (1793), Jovellanos (1795), Sanchis Abella (1795), Muñoz (1799), Jaramillo (1800) y Mata (1805)

12 En el presente trabajo nos vamos a ocupar de analizar la conformación de la parte dedicada a la sintaxis en los tratados escolares ya referidos. Al igual que ocurre con otros ámbitos de la historiografía lingüística española, la teorización sintáctica no ha recibido la atención que hubiera sido deseable, ya que, aunque algunos autores se han dedicado a ella de forma parcial, aún carecemos de un estudio de conjunto que examine las diferentes etapas en su evolución, los contenidos que la integran, etc.

13 Nosotros vamos a intentar con este breve estudio iluminar una parcela de la tradición gramaticográfica española.

\section{La sintaxis}

14 La doctrina sintáctica en el XVIII es heredera de la tradición anterior ; así, encontramos obras como las de Benito Martínez Gómez Gayoso ([1743]) y la Academia (1771), en las cuales se hace patente el peso de la tradición nebrisense. Sin embargo, sí que se produce una paulatina evolución. La obra de Benito de San Pedro, Arte del Romance Castellano (1769) evidencia este hecho en dos aspectos: una mayor importancia del corpus como base de la descripción sintáctica (Lliteras 1997), derivada de su preocupación didáctica, y una mayor reflexión sobre los fenómenos sintácticos que le lleva a admitir dentro de la sintaxis cuestiones que para otros autores son apreciaciones de tipo formal o morfológico, como la explicación de los casos o la clasificación de los verbos. Esta evolución es, a nuestro entender, fruto de una mayor reflexión por parte de los gramáticos sobre la propia lengua ; una reflexión que nace del hecho de que los autores son muy conscientes de la dificultad que conlleva explicar la sintaxis de una lengua, la castellana, con los instrumentos de otra, la latina. Esto les lleva a buscar nuevas formas de aproximarse al hecho sintáctico, entendido, al igual que antaño, como construcción, pero con la diferencia de que, ahora, no se trata tanto de un elemento auxiliar y la sintaxis cobra una gran importancia. Este hecho se irá afianzando a lo largo del siglo XVIII e iniciará el camino hacia la situación actual: mientras que en el siglo XVIII se dedica una cuarta parte de la extensión de la gramática a la sintaxis, hoy, concretamente la Academia, le dedica las tres cuartas partes de su Gramática.

15 El análisis de los aspectos sintácticos resulta un poco más complicado que el resto de las partes de la gramática. Para empezar, la morfología, llamada en el periodo principalmente analogía (Lliteras 1996), sigue siendo la parte más importante de la gramática, con un desarrollo mucho mayor en las obras, hasta el punto de que algunos manuales para las primeras letras, como el de Castillo (1787) o el de Balbuena (1791) sólo incluyen este apartado. Por otro lado, las aportaciones de verdadero interés 
sintáctico no se hallan únicamente contenidas en el apartado dedicado a la sintaxis, sino que en muchísimas ocasiones se encuentran en la analogía, ya que esta constituye una verdadera morfosintaxis, lo cual se debe, principalmente al peso del modelo grecolatino (Gómez Asencio 2001). En el periodo que abarcamos, la dependencia de la sintaxis castellana de la latina es muy importante; en este sentido, la explicación discurre tan próxima que algunos autores redactan manuales conjuntos como es el caso de González Valdés (1791), Sanchis Abella (1795) o los Principios de la sintaxis hispano-latina de Tomás Martínez (circa 1795). Así, tanto González Valdés como Sanchis Abella se limitan a resaltar aquellos casos en que la teoría latina y la teoría castellana no coinciden: "Nuestra lengua conviene en su construcción con la latina mucho más en las concordancias que en el régimen: y así solo hablaremos de los idiotismos en que se aparta" (González Valdés 1791-III : 39).

La sintaxis, sus contenidos, su estructuración, su cuerpo doctrinal, se va construyendo a lo largo del periodo que abarcamos ; ese carácter propio que le atribuyen los latinistas, esos particularismos, la convierten en un lugar que se aparta verdaderamente del modelo, para el que hay que buscar nuevos contenidos. De ahí surge una verdadera amalgama de tradición y modernidad, de viejas concepciones latinas y nuevas nociones filosóficas, de errores e imprecisiones, pero también de un firme deseo didáctico que, como indicamos, se convierte en la fuerza motriz de la evolución teórica.

17 Las definiciones que ofrecen los autores del periodo apenas van a sufrir variación en cuanto a las nociones consideradas, que se pueden reducir a :

- orden

- colocación, composición / unión, trabazón, enlace - construcción

- dependencia

18 Sin embargo, el tratamiento particular que den a cada uno de estos aspectos va a ser determinante para la composición del cuerpo doctrinal. Vamos a ocuparnos principalmente de dos aspectos : el orden y la construcción, para pasar después a la ampliación de las estructuras del lenguaje susceptibles de ser estudiadas desde un punto de vista sintáctico.

\section{El orden}

La importancia de las cuestiones de orden en el apartado sintáctico es indiscutible; no en vano, Nebrija había equiparado orden a sintaxis :

La cuarta [Parte de la Gramática] los griegos llamaron Syntaxis, los latinos costrución; nos otros podemos la llamar orden. A esta pertenece ordenar entre sí las palabras 暲 partes de la oración (Nebrija [1492] : 118).

Agora, en este libro cuarto, diremos cómo estas diez partes se an de aiuntar 㺃 concertar entre sí. La cual consideración, como diximos en el comienço de aquesta obra, los griegos llamaron syntaxis ; nos otros podemos dezir orden o aiuntamiento de partes (Nebrija [1492] : 215).

20 Esta equiparación es asumida por la Academia en la primera edición de la gramática y se convierte en un lugar común para los gramáticos del momento :

Esta unión, trabazón, ó enlace, se llama entre los gramáticos sintaxis, ó construcción, y sus reglas se reducen á declarar el orden con que deben juntarse las palabras para expresar con claridad los pensamientos (GRAE [1771] : 232).

La ordenación que artificialmente tienen las cosas entre sí (Diccionario Usual 1780, s.v.SINTAXIS) 
El orden como disposición de elementos en la oración podía ser de dos formas :

- natural, regular o propio

- figurado o irregular

Esta distinción pasa a ser el fundamento que articula la sintaxis en dos tipos : sintaxis natural y sintaxis figurada. La sintaxis natural o regular responde a dos posibilidades :

1.- Observar las reglas de la gramática. Así aparece en Jaramillo (1793, 1798 y 1800)

o Muñoz (1793 y 1799), entre otros.

2.- Seguir el « común y regular modo de hablar », como señala Ballot (1796: 124).

Para este autor «no hay un orden fixo de colocar las palabras, ni reglas para

invertirlas » (idem : 149).

En ambos casos, - incluso tras el novedoso reconocimiento de Ballot - los autores adoptan una serie de principios que afirman extraer de la naturaleza misma de las cosas : se trata de una ordenación basada en la lógica, aunque también, en ocasiones, de un orden jerárquico no sólo lógico sino semántico, por ejemplo, se indica que el sustantivo antecede al adjetivo " porque antes es la sustancia que la calidad » o que el sujeto va antes que el verbo "porque antes es el agente que la acción» y así sucesivamente. Para Ballot, además, « las palabras deben seguir siempre el orden que llevan las ideas, guardando prioridad de tiempo, lugar, calidad, \&c.; así diremos: mañana y tarde, Dos años, tres meses, dos semanas y un día... » (idem : 150).

En principio, todo lo que no sigue ese orden es sintaxis figurada. Su objetivo es reducir las irregularidades sintácticas a un esquema regular por medio de ciertas figuras de construcción ; esto responde al deseo de claridad, regularidad y simplicidad que mueve a los gramáticos del periodo, influenciados por las corrientes racionalistas.

En este apartado se recogen todas las desviaciones del orden natural o propio e intentan explicarse, aunque no desde una perspectiva puramente gramatical, sino desde el uso retórico y el recurso a las autoridades del idioma : «[Sintaxis figurada es] la que no sigue las reglas, pero siempre se funda en alguna razón, y en el uso de los autores que han hablado bien la lengua » (Muñoz 1799 : 149).

De nuevo, los autores optan por diversas posibilidades :

1.- Considerar la sintaxis figurada como una desviación orientada a dar "gracia y ornato", "elegancia" o incluso "brevedad", es decir, aproximarse de forma activa a la retórica (i.e. Jaramillo, Torio, Ballot o Muñoz).

2.- Considerar la sintaxis figurada como desviaciones que es necesario explicar y regularizar, sin entrar en otras consideraciones (i. e. Jovellanos o Rubel).

3.- Considerar la sintaxis figurada como el resultado una ordenación "personal" : " cada uno ordena como mejor le acomoda según el juicio que haya formado de las cosas, o conforme al afecto que lo haya poseído...» (Herranz 1815 : 68).

De cualquier forma, los gramáticos coinciden en su totalidad al reducir esas desviaciones a cuatro : pleonasmo, elipse, hipérbaton, silepsis. Es obvio que no todas ellas responden a una cuestión de orden, como el hipérbaton, sino que se trata de dar cuenta de las alteraciones sintácticas más habituales, recurriendo para ello a las herramientas retóricas.

En opinión de Gómez Asencio (1981:80), «la sintaxis figurada permaneció en las gramáticas como rémora, como símbolo de la deuda que la Gramática había contraído con la Retórica por haber surgido en un principio con ella"; coincidimos en gran medida con el profesor Gómez Asencio, aunque creemos necesario establecer algunas precisiones. La relación entre gramática y retórica -así como la relación entre 
gramática y lógica-, lejos de suponer una rémora, una especie de secuela, entra dentro de una comprensión amplia de las disciplinas humanísticas. Éstas eran entendidas en la época, especialmente en el caso de las disciplinas lingüísticas, como un recorrido que conduce hacia un cierto grado de complejidad y precisión en el uso de las palabras y la adquisición de un saber, un recorrido que permite a quien lo realiza acceder a una cultura formadora del espíritu. De ahí que la gramática castellana, la gramática escolar, entre desde sus inicios en esa articulación, y se busque adquirir una competencia lingüística o literaria, es decir, se oriente hacia la maestría del discurso castellano y la composición castellana, concebidos como ejercicios literarios. La imitación es la clave de este aprendizaje : se trata de familiarizarse, por la lectura y la explicación, con los textos clásicos, de interiorizar y reproducir los procedimientos: modelo retórico. Veámoslo con un ejemplo : Muñoz Álvarez, quien tiene una academia de humanidades en Sevilla, lo expresa de la siguiente forma :

Los que en sus tiernos años lograron una educación literaria, o después a costa de fatigas se han formado a sí mismos ; los que están convencidos de la íntima unión y enlace de las letras humanas; y de cuanto dicen Cicerón y Quintiliano sobre este punto; los que penetraron la fuerza de aquel axioma pocos preceptos y mucha práctica... ; estos no extrañarán la enseñanza simultánea de los varios ramos de la literatura, y lejos de creerla nociva u origen de superficialidad o confusión, la tendrán por un medio utilísimo para amenizar la aridez de los estudios de lenguas, y hacer más sólidos los conocimientos de todos ellos, ayudándose mutuamente unos a otros [...] (Alea 1804-II: 222-223).

Esos ramos de la literatura se comprenden bajo el nombre genérico de Bellas Letras y son la gramática, la retórica y la poética. Algo similar propone Jovellanos para el Instituto Asturiano de Mineralogía, en su Curso (1795) y así toda una serie de autores y planes de estudios de la época.

La cada vez mayor autonomía de la gramática castellana, especialmente en los primeros estadios de formación, y la mecanización de un aprendizaje que pierde mucho de su valor como "formador del espíritu" hará innecesarios los lazos entre las diversas materias humanísticas, y la deslatinización gramatical (Gómez Asencio 2001) se convierte también en una desretorización, que hace innecesario el recurso a las figuras.

El orden tiene gran importancia también por cuanto sirve a los autores más tradicionales de manifestación de las relaciones de dependencia entre las palabras: « las que están antes rigen: las que están después son regidas » (GRAE [1771] : 235). Esto es una herencia directa de la tradición latina, ya que al ser el latín una lengua de orden fijo, la posición de la palabra constituía, junto con la flexión casual, la marca externa de la relación sintáctica entre dos palabras.

Los gramáticos latinistas, como Sanchis, convierten el orden en el centro de su doctrina sintáctica. El castellonense, de hecho, organiza este apartado desde el punto de vista del latín, más que desde la propia lengua, y articula la sintaxis desde el sistema de análisis latino : reconocer las formas, analizar/ordenar, traducir. Para este autor, la sintaxis es toda una, latina y castellana, y su afán didáctico le lleva a considerar el análisis de la proposición castellana al mismo nivel de la latina: su método se basa en analizar la oración asignándole un número a cada constituyente y a partir de ahí, explica las relaciones que se establecen :

${ }^{6}$ escaso ${ }^{5 .}$ socorro ${ }^{2 \cdot}$ dan $\operatorname{los}^{1 \cdot}$ ricos a los ${ }^{4 \cdot}$ pobres 

los puramente colocacionales $u$ ordenadores en la definición, que no en el tratamiento, de la sintaxis ; así como podemos apreciar, aparece en algunas gramáticas la idea de que la sintaxis no sólo trata de colocar o unir las palabras, el orden que han de seguir y las reglas que rigen ese proceso, sino que toda ella tiene un objetivo: 'expresar con claridad los pensamientos'. Esta idea aparece aún más claramente en la definición de González Valdés (1798: 6) : « En la construcción, coordinación, composición o sintaxis, se 
enseña el orden respectivo [...] de las palabras, según el orden de las ideas en la oración ».

La identidad entre construcción y sintaxis es bastante habitual en nuestros gramáticos, aunque podemos señalar algunas cuestiones interesantes. En el diccionario de la Academia de 1791, encontramos ciertas discrepancias en las definiciones, frente a lo que ocurre en las distintas ediciones de la gramática publicadas hasta ese año (1771, 1772, 1781 y 1786) ; en la voz SINTAXIS, aparecen dos acepciones diferentes : « Modo de coordinar las oraciones, o el tratado de gramática, que enseña los casos que pide cada verbo y las oraciones latinas. Constructio » y « La ordenación que artificialmente tienen las cosas entre sí. Syntaxis "; mientras que la voz CONSTRUCCIONaparece definida como « la recta composición de las partes de la oración entre sí. compositio, constructio ». Es decir, nos encontramos ante dos posibilidades :

Constructio -> Sintaxis

Constructio $\rightarrow$ Construcción

Ballot (1796: 124) adopta una perspectiva similar en su definición: «Entiendo [por sintaxis] el segundo libro de la gramática, que señala la concordancia y el régimen, y el modo de coordinar las partes de la oración entre sí ", es decir

Sintaxis $=$ concordancia + régimen + construcción

Ahora la construcción no se entiende como término sinonímico de sintaxis, sino como una de las partes que la componen. La influencia de los teóricos franceses, como Du Marsais, es de vital importancia, pese a lo tardío de su admisión. La Academia, en su edición de 1796, elimina la noción de construcción/sintaxis de su definición y añade el subapartado « construcción »:

La construcción de las partes de la oración es otra especie de dependencia que las une, no con tanta precisión como el régimen, sino con alguna mayor anchura y libertad; ya añadiendo unas, ya introduciendo otras entre las que van enlazadas por el régimen, para dar energía a las oraciones, y evitar la uniformidad que resultaría, si se guardaran constantemente en el uso las reglas del régimen y concordancia de las palabras (GRAE 1796 : 326-327).

Para Muñoz, sin embargo, no se trata tanto de ampliación del régimen, o régimen segundo, como lo llama Herranz (1815), sino del estudio de la estructura oracional : « de la observación de la concordancia y el régimen resulta la buena estructura de las oraciones que es el complemento de la sintaxis. Esta buena estructura suele llamarse construcción, y algunos la tienen por el tercer fundamento de esta parte de la gramática » (1799: 155). En este apartado se ocupa, según sus propias palabras « de las varias especies de las oraciones» y su clasificación «del modo más racional, desterrando la insulsa nomenclatura que han introducido algunos gramáticos en esta materia ».

\section{De la palabra a la oración}

La inclusión de la construcción como apartado independiente, en cualquiera de los dos sentidos señalados, manifiesta el paso de una sintaxis de palabras a una sintaxis oracional. 

Muñoz Álvarez « la dependencia que tienen en la oración unas partes con otras. De manera que aquella palabra (y a veces alguna oración) cuyo sentido está pendiente de alguna otra palabra u oración, se dirá que está regida de ella » (1793 : 121) o en la obra de Torio de la Riva, quien en su definición de oración señala : « si no depende de otra se llama principal. Si depende de otra se llama incidente» (1798: 366). Incluso apuntan la existencia de oraciones simples «la que solo tiene un verbo" frente a oraciones compuestas « la que tiene dos o más verbos unidos por atadura » (Sanchis Abella 1797 : 15).

Esta perspectiva se ve reforzada por la posición del verbo como elemento rector de la oración ; así se aprecia, por ejemplo, en Torio (1798: 366), quien distingue claramente entre periodo y oración: "[periodo es] un ajuntamiento o unión de palabras que contienen sentido perfecto. [El periodo se compone] de miembros que se llaman oraciones (...) las cuales son tantas cuantos son los verbos determinados que contiene el periodo $"$. 
53 Esta idea posibilita la aparición de diversas clasificaciones de las oraciones, según su verbo y según la conjunción que las introduce, lo cual es muy novedoso. Pero nosotros nos preguntamos ¿A qué se debe esto? ¿Qué genera la necesidad de clasificar las oraciones, tipificarlas y determinar cuál es su composición según el tipo al que pertenecen? La respuesta, nuevamente, hay que buscarla en el didactismo y en la aparición de una técnica nueva, un dispositivo escolar (Chevalier 1974) : el análisis gramatical.

Lo que en principio no es sino una forma de ejemplificar la teoría sintáctica y que en muchas ocasiones no pasa de ser un análisis morfológico, se convierte en un ejercicio razonado destinado a consolidar el dominio de las estructuras sintácticas. Para Jovellanos, quien introduce un tratado de análisis del discurso se trata de un análisis lógico ; por una parte, se trata de análisis del discurso como pensamiento, es decir, de analizar las partes de un discurso según los diversos pensamientos o ideas expuestos en él ; para ello, es muy importante el uso de la puntuación, como forma de estructurar las ideas contenidas en un discurso. En esta misma parte, y siempre tomando como referencia el significado, la articulación semántica del discurso, Jovellanos distingue entre proposición principal que " presenta por sí sola un sentido completo » y subordinada « no forma sentido alguno, sino en cuanto se une a la proposición principal », la función de la subordinada es, pues, « desenvolver » la principal ([1795] : 152).

En segundo lugar, pasa a analizar la proposición ; esta se articula según las operaciones de nuestro entendimiento : tras percibir la sensación de dos ideas u haberlas atendido nuestro entendimiento, se pasa a compararlas. El juicio procede de la comparación de dos ideas. Representamos por medio de palabras las dos ideas de que consta el juicio y una tercera representará la relación entre ambas :

Sujeto <-> Verbo<->Atributo

En este apartado, introduce una diferenciación fundamental entre proposiciones simples y compuestas, siempre atendiendo al sentido, en este caso a los juicios que comprende la proposición ; al final, analiza cada una de las partes de la proposición-juicio y añade algunas observaciones sobre las palabras compuestas, los adverbios, pronombres y conjunciones, que representan diversas ideas.

57 Para otros autores, como Herranz, sin embargo, se trata de « el examen que se hace de alguna proposición o periodo considerando por menor las oraciones de que consta, si son primeras o segundas, si naturales o figuradas, con expresión de las partes que las constituyen, y de la concordancia, régimen y construcción que recíprocamente tengan entre sí » (1815: 84), es decir, de un ejercicio puramente gramatical de segmentación y descripción formal de textos, que más adelante dará paso a la producción. La necesidad, por tanto de una taxonomía que dé cuenta de todas las posibilidades combinatorias, tanto de palabras (aparición de las nociones de régimen principal, régimen secundario o añadido, circunstancia, etc.) como de oraciones, se hace obligatoria en pro del didactismo.

\section{Conclusión}

Queremos concluir esta necesariamente breve visión de la sintaxis en la gramática escolar de finales del siglo XVIII y principios del XIX insistiendo en la idea que ha articulado todo nuestro trabajo : la teoría sintáctica del castellano evoluciona porque se 
utilizan viejas respuestas a nuevos problemas y el traje latino no acomoda bien al cuerpo castellano. Así, se opta por ir adecuando conceptos y técnicas a la realidad de la lengua para poder explicarla mejor y proporcionar al alumno toda una serie de recursos teóricos que le permitan aproximarse con facilidad al hecho lingüístico, tanto desde el punto de vista del receptor como desde el punto de vista del emisor. La introducción de la práctica del análisis conlleva una organización más rigurosa de los diversos aspectos que hasta ese momento se situaban en el marco de la sintaxis y la aparición de nuevos conceptos y, por tanto, una ampliación necesaria e inevitable de la doctrina sintáctica.

\section{BIBLIOGRAFÍA}

\section{Fuentes primarias}

ABADÍA, José Miguel. 1804. «Proyecto del plan de enseñanza y educación que da a sus alumnos o pupilos en su Academia privada de latinidad y demás ramas de humanidades don Agustín Muñoz Álvarez ». Variedades de ciencias, literatura y artes II-10. 217-230.

ANÓNIMO. $1792^{5}$. Compendio de Gramática Castellana, dispuesto en diálogo con arreglo a la Gramática de la Real Academia de la Lengua para uso de las Escuelas de Primeras Letras. Cádiz : Manuel Ximénez.

BALBUENA Y PÉREZ, José. 1791. Arte nuevo de enseñar a los niños y vasallos a leer, escrivir y contar, las reglas de Gramática, y orthografía castellana, precisas para escrivir correctamente ; y formulario de cartas con los correspondientes tratamientos [...]. Santiago : Ignacio Aguayo.

BALLOT Y TORRES, J. Pablo. 1796. Gramática de la lengua castellana dirigida a las escuelas. Barcelona : J.F. Piferrer.

CRISTÓBAL Y JARAMILLO, Guillermo Antonio de. 1793. Arte nuevo de ortología, gramática castellana, ortografía y calografía. Toledo : herederos de Nicolás de Alcuanzano.

-.1798. Curso de gramática castellana en sólo ochenta días.Madrid: Gerónimo Ortega.

-. 1800. Lecciones de Gramática-Ortografía Castellana según y como lo enseña en su estudio [...]. Madrid : Gerónimo Ortega.

DELGADO Y MARÍN (DE JESÚS Y MARÍA), Santiago. 1790. Elementos de gramática castellana, ortografía, caligrafía y urbanidad, para uso de los discípulos de las Escuelas Pías. Madrid : Benito Cano.

Estatutos del Colegio Académico de Primeras Letras (22 de diciembre de 1780), Archivo Histórico Nacional, Consejos, lib. $1524 \mathrm{n}^{\circ} 77$.

FELIU DE SAN PEDRO, Benito. 1769. Arte del romance castellano. Valencia : Imprenta de Benito Monfort.

GONZÁLEZ VALDÉS, Juan Antonio. 1791. Gramática de la lengua latina y castellana. Dividida en sus quatro partes: Analogía, Etimología, Prosodia y Construcción, principios indispensables para entender una $y$ otra con fundamento en todas sus edades, facilitados y combinados alternativamente los unos con los 
otros, con arreglo al uso de los escritores de prosa y verso, y en la Cédula real de 23 de junio de 1768. Madrid : Imprenta Real.

HERRANZ Y QUIRÓS, Diego Narciso. 1815. Elementos de gramática castellana. Madrid.

JOVELLANOS, Gaspar Melchor (de). [1795] 1963. Curso de Humanidades Castellanas, en Obras Publicadas e Inéditas de don Gaspar Melchor de Jovellanos. Madrid: Atlas (Biblioteca de Autores Españoles, 46 ; eds. por Cándido Nocedal).

MARTÍNEZ, Tomás. (s.d.). Principios de la sintaxis hispano-latina. Barcelona : Francisco Suriá y Burgada.

MARTÍNEZ GÓMEZ GAYOSO, Benito. [1743] 1763. Gramática de la Lengua Española reducida a breves Reglas y fácil méthodo para instrucción de la juventud. Madrid : Juan de Zuñiga.

MATA Y ARAUJO, Luis (de). 1805. Nuevo epítome de Gramática Castellana, o verdadero y sencillo método de enseñar el castellano por principios generales a la filosofía común de las lenguas, arreglado también a la latina para facilitar su estudio. Madrid : Imprenta de la Administración del Real Arbitrio de la Beneficencia.

MUÑOZ ÁLVAREZ Agustín. 1793. Gramática de la lengua castellana : ajustada á la latina para facilitar su estudio / por Agustin Muñoz Alvarez. Sevilla : Imprenta de Vázquez y Viuda de Hidalgo.

-. 1799. Gramática de la lengua castellana : ajustada á la latina para facilitar su estudio, 20 edición corregida y mejorada por su autor, y aumentada con una noticia preliminar de las Humanidades, y un apéndice sobre el genio, idiotismos, edades y autores célebres de la lengua castellana, por D. Joseph GarciPérez de Vargas. Sevilla: Juan de la Puerta.

NEBRIJA, Elio Antonio (de). [1492] 1989. Gramática de la lengua castellana (Edición de Antonio Quilis). Madrid : Editorial Centro de Estudios Ramón Areces.

QUINTANA,Manuel José et al. 1979. « Informe de la Junta creada por la Regencia para proponer los medios de proceder al arreglo de los diversos ramos de la Instrucción Pública - Cádiz, 9 de septiembre de 1813 ». In : Historia de la Educación en España. Textos y Documentos - Del Despotismo Ilustrado a las Cortes de Cádiz I-373-414 (Madrid : MEC).

REAL ACADEMIA ESPAÑOLA. [1771] 1984. Gramática de la lengua castellana (Madrid, Joachin Ibarra. Edición facsimilar, con introducción y apéndice documental de Ramón Sarmiento). Madrid : Editora Nacional.

-. $1796^{4}$. Gramática de la lengua castellana (4º ed. corregida y aumentada). Madrid : Viuda de Ibarra. RUBEL Y VIDAL, Juan. 1797. Compendio de gramática en lengua castellana, dispuesto en preguntas y respuestas. Y con arreglo a la quarta edición de la Gramática que la Real Academia Española publicó en el año próximo pasado de 1796, por D., Maestro Profesor de primera educación y Revisor de Letras. Barcelona : Sierra y Martí.

SANCHIS ABELLA, Joaquín. 1795. Explicación de los principios de la gramática castellana y latina, conocimiento de las palabras en castellano y latín, modo de hallarlas en el manejo de diccionarios y ordenarlas, hablando, escribiendo y traduciendo, y la noticia de los guarismos romanos y arábigos. Valencia : Francisco Burguete.

TORIO DE LA RIVA, Torcuato. 1798. Arte de escribir por reglas y con muestras, según la doctrina de los mejores autores antiguos y modernos, estrangeros y nacionales : Acompañado de unos principios de Aritmética, Gramática y Ortografía castellana, Urbanidad y varios sistemas para la formación y enseñanza de los principales caracteres que se usan en Europa. Madrid : Viuda de Ibarra. 
-. $1802^{2}$. Arte de escribir por reglas y con muestras [...]. $2^{\text {a }}$ Edición. Madrid : Viuda de Ibarra.

\section{Estudios}

CASADO VELARDE, M. (ed.). 1996. Scripta Philologica in memoriam Manuel Taboada Cid (vol. I).

Coruña - Universidade da Coruña.

CHEVALIER, J.-Cl. 1979. « Analyse grammaticale et analyse logique, esquisse de la naissance d'un dispositif scolaire ». Langue Française 41. 20-34.

GARCÍA FOLGADO, M. J. [en prensa]. « La enseñanza de la gramática española en la segunda mitad del siglo XVIII : la obra de Guillermo Antonio Cristóbal y Jaramillo ». In : V Congreso de Lingüística General (León, 5 a 8 de marzo de 2002).

GINEBRA i SERRABOU, J. 1996. L'obra gramatical d'Antoni Febrer i Cardona (1761-1841). Maó : Institut Menorquí d'Estudis.

GÓMEZ ASENCIO, J. J. 1981. Gramática y categorías gramaticales en la tradición española (1771-1847). Salamanca : Ediciones Universidad.

-. 2001. «Lo latino en las gramáticas del español ». In : Actas del II Congreso Internacional de la Sociedad Española de Historiografía Lingüística (ed. por Marina Maquieira Rodríguez, Mª Dolores Martínez Gavilán y Milka Villayandre Llamazares).Madrid : Arco/Libros. 35-54.

LLITERAS, M. 1996. « De la etimología a la analogía en la historia gramatical española ». In :

CASADO VELARDE, M. (ed.). 131-141.

-. 1997. «Sobre la formación del corpus de autoridades en la gramática española ».

Historiographia Linguistica XXIV-1/2.57-72.

\section{NOTAS}

1. Este trabajo se inscribe en el proyecto BFF2002-00230, La codificación gramatical de la lengua española, del Ministerio de Ciencia y Tecnología de España.

2. Archivo Histórico Nacional, Consejos, lib. $1524 n^{\circ}$ 77. Están editados en Madrid, por Isidoro Fernández Pacheco, 1781. Puede consultarse, asimismo la Novísima Recopilación de las leyes de España, libro VII, título I, ley IV.

3. Nos referimos al Informe de la Junta creada por la Regencia para proponer los medios de proceder al arreglo de los diversos ramos de la Instrucción Pública, presentado en Cádiz, el 9 de septiembre de 1813 y elaborado por M. J. Quintana.

\section{RESÚMENES}

Le dernier quart du XVIII ${ }^{\mathrm{e}}$ siècle espagnol voit s'accroître dans des proportions importantes la production grammaticale destinée à l'enseignement de la langue maternelle. Cette production a deux objectifs principaux : accompagner l'enseignement de la lecture et de l'écriture, constituer une propédeutique pour l'apprentissage du latin dans l'enseignement secondaire. Ces buts 
reposent sur la conviction que la langue est un élément important dans l'échange social et culturel, et de ce fait, qu'elle doit être employée avec correction. Le moule du latin pèse encore de tout son poids, mais, peu à peu, les auteurs abandonnent les recours explicatifs théoriques alors habituels en faveur d'une description plus adaptée de la langue. Cet effort devient de plus en plus évident, en particulier dans les pages que ces grammaires consacrent à la syntaxe, partie qui atteint le plus haut degré de complexité depuis les débuts de la grammatisation de l'espagnol.

During the last quarter of the Spanish eighteenth century, the grammatical production intended for the teaching of the mother tongue increased in significant proportions. This production has two main objectives: to support the teaching of reading and writing, and to establish a foundation course for the learning of Latin in secondary education. These goals are based on the conviction that language is an important element in the social and cultural exchange, and therefore, it should be used correctly. The Latin influence is still evident but, little by little, the scholars give up the standard theoretical explanatory resources in favour of a more appropriate description of the language. This effort becomes more evident, especially in the pages devoted to this grammar syntax, which reaches the highest degree of complexity from the beginning of the grammaticalization of the Spanish language.

\section{ÍNDICE}

Keywords: Eighteenth century, grammatical contents, grammaticalization, learning Spanish, secondary education, Spain, syntax

Mots-clés: apprentissage de l'espagnol, contenus grammaticaux, enseignement secondaire, Espagne, grammatisation, syntaxe, XVIII siècle

\section{AUTOR}

MARÍA JOSÉ GARCÍA FOLGADO

Universitat de València 